\title{
Notas para una historia del cuerpo Una mirada desde la Educación Física
}

Notes for a history of body.

A look from physical education

\section{Álvaro José Gracia Díaz}

\section{Resumen}

\begin{abstract}
El cuerpo, como nos dice George Vigarello (2005), se ha convertido en objeto de la historia, en virtud de que es sujeto de escenarios materiales y culturales que han cambiado substancialmente a lo largo de los siglos. En este breve bosquejo intentaremos dar una mirada al recorrido del cuerpo, desde la Edad Media, donde el cuerpo es sinónimo de pecado, aun cuando se considere como viva imagen de su creador. De allí miraremos los cambios aún leves que se presentan durante el Renacimiento, donde el cuerpo es el centro del universo y a su vez objeto de belleza. En ese recorrido presentaremos las ideas que sobre el cuerpo llegaron a América, haciendo énfasis en que no surgieron durante el Renacimiento y la modernidad, sino, a través de la Iglesia, fueron dominado en Europa durante la Edad Media, con profundas implicaciones en el campo de la cultura y, particularmente, de la educación.
\end{abstract}

Palabras clave: Cuerpo, edad media, renacimiento, inquisición, colonia, posmodernidad, clero, indios, mestizos, raza, educación.

\section{Abstract}

Key words: $\quad$ Body, Middle Age, Renaissance, Inquisition, colony, postmodern era, clergy, indian, mestizo, race, education.

The body, George Vigarello states, has turned into an object of history, in as much as it is the subject of material and cultural scenarios, which have considerably changed in time. This article aims at remembering historical moments of the body from the Middle Ages, when it was a synonym of sin, even though it was considered to be an image of God. Then, we will take a look at the rather slight changes from Renaissance, where the body was both the center of the Universe and an object of beauty. We will go through the ideas on the body that came to America, emphasizing on the fact that those ideas were not those arisen during the Renaissance and the modernity, but, through Church, those that had predominated in Europe during the Middle Ages, with deep implications in culture, particularly in education.

Fecha de recepción: 3 de septiembre de 2007

Fecha de aceptación: 21 de octubre de 2007

\section{8| Introducción}

\footnotetext{
Licenciado en Educación Física. Especialista en Teorías, Técnicas y Métodos de la Investigación. Magíster en Educación Docencia gica Nacional. algradi333@yahoo.com.
} 


\section{Introducción}

No cabe duda que al hacer un recorrido por la historia de la educación física, el análisis del lugar del cuerpo tanto en las prácticas escolares como en las de la vida cotidiana, es necesario, pues el cuerpo es presencia, no sólo de las prácticas escolares, sino a la vez presencia en todo cuanto el hombre realiza, todo cuanto es producto de su interactuar en sociedad.

\section{El lugar del cuerpo en la Edad Media}

A lo largo de la historia, particularmente durante la Edad Media, el cuerpo fue estigmatizado a partir de las consideraciones platónicas expuestas en el Fedón en las que se afirma que el cuerpo era la cárcel del alma (Platón, 1985). Esta posición negativa del cuerpo fue fortalecida por la religión cristiana, bajo la premisa de que el cuerpo era albergue de pecado.

Por tanto, era deber hallar su purificación, pues aún cuando la fe y la devoción hacia el cuerpo de Cristo habían contribuido a elevar el cuerpo hasta un alto grado de dignidad, convirtiéndolo en sujeto de la historia, "la permanencia de la imagen del hombre pecador recordaba a los fieles la desconfianza hacia el cuerpo que la Iglesia había manifestado" (Gélis, 2005: 30); por ello, durante la Edad Media, el discurso cristiano se movió entre el ennoblecimiento y el desprecio del cuerpo, tanto que invadió espacios de la vida privada, como en la Europa del siglo XI, donde la Iglesia ejercería un control mayúsculo sobre los fieles mediante la imposición de normas restrictivas, como la regulación del matrimonio y de la sexualidad, que implicaría la limitación del matrimonio entre parientes (Fontana, 1994: 52).

Aun así, a principios del siglo VII, Isidoro de Sevilla argumentó que "es propio de varones ya perfectos obrar la justicia no a imitación de un santo cualquiera, sino contemplando la misma Verdad, a cuya imagen han sido creados" (Sevilla, 1971). El hombre debía ser imagen y semejanza de su creador, como lo advertirían los teólogos en la Edad Media, y cuyos postulados se harían más evidentes en el pensamiento de Tomás de Aquino.

En este sentido, Tomás de Aquino (2001), de acuerdo con los principios aristotélicos, establecía que no toda potencialidad es materia ni toda actualidad es forma sustancial, pues la materia se encontraba exclusivamente en las realidades sujetas a generación y corrupción, y por tanto, el alma humana y los ángeles carecían de ella. Además, la materia prima "es pura potencia pasiva, sin actualidad alguna", en consecuencia, "no se dan en ella rationes seminales ni disposición alguna”. Por otra parte, la forma sustancial confería a la materia prima su determinación específica completa; es decir, toda la actualidad y perfecciones del ser en el orden esencial. De ahí, entonces que no pudiera coexistir con ella ninguna forma incompleta, ni una forma del cuerpo, ni multiplicidad de formas sustanciales subordinadas: "por eso decimos que en este hombre no hay otra forma sustancial que su alma racional, y que por ella no sólo es hombre, sino animal y vivo y cuerpo y sustancia y ser" (Aquino, 2001: 670).

Como se advierte, Tomás de Aquino recurría al relato del Génesis y a San Agustín para explicar el origen del hombre, al mismo tiempo que a los postulados aristotélicos de las causas y las conclusiones establecidas sobre la naturaleza del hombre. Por ello aclaraba "la primera formación del cuerpo humano no pudo proceder de una potencia creada, sino directamente de Dios" (Aquino, 2001: 696), pues Dios, "aunque absolutamente inmaterial, es el único que puede, por su poder, producir la materia creando". Y concluía en la cuestión 91, que sólo Dios podía "producir la forma en la materia prescindiendo de toda anterior forma material. Por eso, los ángeles no pueden cambiar los cuerpos en sus formas a no ser por medio de algunos gérmenes, como dice Agustín [...] Así, pues, porque nunca había sido hecho un cuerpo humano por cuya virtud pudiera ser formado por generación otro ser semejante en la especie, fue necesario que el primer cuerpo humano fuera hecho directamente por Dios (Aquino, 2001: 844).

Paradójicamente, como nos recuerda Fontana (1994), el cuerpo de la mujer fue satanizado en la Edad Media, tanto que la desnudez era motivo de consideración herética. Sobre la mujer, el Doctor Angélico advertía en la cuestión 92, artículo 4. ${ }^{\circ}$ de su Summa Theologica, que, "parece que la mujer no fue hecha directamente por Dios", porque "ningún individuo producido de otro específicamente semejante es hecho directamente por Dios. La mujer fue hecha del varón, que es de la misma especie. Por tanto, no fue hecha directamente por Dios" (Aquino, 2001: 852).

Ello habría de influir directamente en las prácticas de vida, en la apreciación de la mujer y en la generación del machismo. En esa dirección, la religión, como habría de esperarse, fue determinante en el uso de los vestidos. Por razones de pudor y de mantener "sus vergüenzas" ajenas a las miradas, los monjes llevaban largas sayas cosidas a un lado y sobre ellas largos hábitos con capucha. Los largos vestidos hasta los tobillos se convirtieron en una característica monástica y también de los ecle- 
siásticos (Rösener, 1990). Así, la cultura de la baja Edad Media se presenta como un constante duelo entre fuerzas opuestas en el que se manifiesta con mayor fuerza el duelo entre el espíritu caballeresco y el espíritu burgués, y el duelo entre el sentimiento religioso y el sentimiento profano: una constante lucha entre el "bien" y el "mal" (Romero, 2006).

\section{El cuerpo en el Renacimiento}

Durante el Renacimiento el cuerpo adquiere una serie de dispositivos imaginados independientemente de la influencia de los planetas, de las fuerzas ocultas, de los amuletos o los objetos preciosos y, de alguna manera, de Dios. Los mecanismos de ese cuerpo se "desencantan", sometidos a la nueva visión de la física, explicados por la ley de las causas y los efectos. Ello no significa que desaparecieran definitivamente las creencias (sobre medicina popular, hechicería, o las de los cuerpos dominados por lo impensable), y aún menos las referencias a lo sagrado (Vigarello, 2005). En todo caso, entre los siglos XIV y XVI, la educación del cuerpo se enfocó en el cuidado de la salud, cimentado en el comportamiento simple, mucho aire, ejercicio, dormir y un régimen de vida sencillo, como recomendara John Locke (1986).

No podemos negar los aportes de Juan Jacobo Rousseau en la educación del cuerpo, quien aun en su concepción ilustrada, mantuvo una oposición de rechazo a la racionalidad, no en cuanto a la razón en sí, ya que la consideraba como el bien más preciado del ser humano, potencialmente desarrollable y en consonancia con la naturalidad cotidiana. En este sentido, las máximas educativas de Rousseau serán enseñar por el “interés natural del niño y nunca por el esfuerzo artificial" y la educación activa, que permitiera aprender por nosotros mismos con el uso de la razón, del ingenio, innovando e interrelacionando nuestras ideas (González Boto, 2003).

Al mismo tiempo, la permanente búsqueda de equilibrio forjada desde el humanismo ubica el cuerpo junto a otros valores humanos, lo que explica que el cuerpo sea el objeto de atención tanto de maestros como de artistas, pintores y escultores. Así paulatinamente, la belleza va adquiriendo consistencia e inmediatez. Alrededor de 1420, Masaccio concibió una nueva manera de restituir la presencia carnal, el juego con las masas físicas, el color, el tamaño de las formas y las redondeces, introduciendo la belleza en la modernidad (Vigarello, 2005 p, 24). El Renacimiento representó una mutación del pensamiento figurativo, dando lugar al realismo que bruscamente tomaron las formas de los cuerpos que habían sido pintados en la Toscana del siglo XV.
En el mismo sentido, se hizo presente una especie de examen sobre las pulsiones y los deseos, lo que significó el control de las buenas maneras y de la sociabilidad; una preocupación por limar las violencias y de vigilar los propios gestos en el universo de lo íntimo, tales como la forma de moverse, las maneras de comportarse, la sexualidad y los juegos (Vigarello, 2005: 24). Contrariamente, en la España de mediados del siglo XVI, la simple alusión a las relaciones sexuales era severamente castigada por la Inquisición. Todo lo que tuviera que ver con las intimidades del cuerpo despedía un terrible olor de azufre que era necesario purificar (Kamen, 1999). Esos prejuicios e imaginarios, que de alguna manera gracias a los humanistas, los artistas y científicos renacentistas, se irían desvaneciendo lentamente de Europa, se manifestarían de manera patente en la conquista y colonización de América.

\section{El cuerpo en América, una extensión de los prejuicios}

La España que conquistó América guardaba todos lo temores y prejuicios medievales sobre el cuerpo. Las obsesiones sobre la desnudez que poseían a los españoles de finales del siglo XV, se hacen evidentes en las apreciaciones que tiene Cristóbal Colón en su primer viaje. El jueves 11 de octubre de 1492 escribe: "ellos andan todos desnudos como su madre los parió, y también las mujeres, aunque no vi más que una bastante moza. Y los que yo vi eran todos mancebos, que ninguno vi de más de treinta años de edad. Muy bien hechos, de muy hermosos cuerpos y muy buena caras. Los cabellos gruesos casi como sedas de colas de caballo, y cortos, los cabellos traen por encima de las cejas" (Colón, 1982: 16-31).

Como habría de reconocer Bartolomé de Las Casas (1991), los españoles, que tenían nulo sentido de la diferencia, no sabían quiénes eran los indígenas americanos. Aun así, llegaron a confundirlos con los habitantes de la India y por ello les llamaron "indios". Con todo, los españoles en su afán de dar una definición a los indígenas veían lo que consideraban que debían ver: “[...] decían los cristianos que no había comparación, así en los hombres como en las mujeres, y que eran blancos más que los que habían visto, y señaladamente decían que habían visto dos mujeres mozas, tan blancas como podían ser en España" (Las Casas, 1991).

Sin embargo, el racismo y los prejuicios sobre la desnudez se hacían manifiestos a la hora de catalogar a los indígenas americanos. Ginés de Sepúlveda, confesor de Carlos V, aseguraba en 1547 que a los indígenas había 
que hacerles la guerra si no se sometían, pues en su consideración los indios estaban más cerca en parecido de los monos que de los hombres. Cosa distinta pensaba Bartolomé de Las Casas, para quien "todas las naciones del mundo son hombres" (De Roux, 1990). Aun así, un siglo después, el jesuita Gilbert Chinard, en 1634, realizó en detalle una descripción de los "salvajes" americanos en tierras del Canadá: "si comenzamos por los bienes del cuerpo, diré que están bien hechos, son grandes, derechos, fuertes, bien proporcionados, ágilles, nada afeminados" (Corvalán, 1999).

En todo caso, la España que colonizaba el llamado Nuevo Mundo, no sólo se debatía en medio de prejuicios y temores sobre el cuerpo, sino que hacía manifiesto un comportamiento totalmente distante del sello cristiano con el que se identificaban, pues, ante la ausencia de mujeres españolas en tierras "nuevas", los colonizadores españoles hacían ostensible una doble moral, mediante la práctica del abuso y la promiscuidad: "en el último tercio del siglo XVI, los miembros del cabildo de Ciudad de México obtuvieron licencia real para establecer un burdel, le asignaron un solar adecuado y recomendaron su funcionamiento, tomando en cuenta el pernicioso ejemplo que daban los españoles a los naturales cuando abandonaban sus esposas legítimas y acudían a buscar la compañía de las indias." (Gonzalbo Aizpuru, 2000: 51).

Las cosas eran tales, que "[...] en 1623 Felipe III dispuso la clausura de los lupanares de todas las provincias de la monarquía [...]". Frente a ello, "nadie puso gran empeño en llevarlo a la práctica porque las autoridades locales de cualquier latitud habían comprobado las ventajas de la tolerancia" (Gonzalbo Aizpuru, 2000: 52). Como habría de esperarse, los prejuicios y la doble moral habrían de ser práctica constante en las incipientes escuelas que surgirían durante la Colonia en América.

\section{La educación del cuerpo en la Colonia}

La educación en la Colonia, en lo que implicaba la formación del cuerpo o, en última instancia el cuerpo mismo, era expresión de aquella educación, estaba perfectamente delimitada para atender las "necesidades" u obligaciones de las castas. Así, las familias pudientes contrataron preceptores o tutores para la formación moral de sus hijos, mientras las familias pobres procuraron formar a sus hijos para el desempeño en diversos oficios (García Sánchez, 2007). Estos prejuicios eran manifiestos fuertemente durante la Colonia, al lado del racismo y la exclusión imperantes. En el Nuevo Reino de Granada, en 1780, uno de los requisitos para ser maestro de primeras letras era, entre otros, que sobre el interesado para ser maestro se rindiera "informe de tres testigos sobre su domicilio, vida, costumbres y limpieza de sangre" (Martínez Boom y Silva, 1984: 43)

Ello era evidente, si tenemos en cuenta que la primacía de lo blanco debía lucir sólo entre aquellos que se consideraran de origen español, aun cuando fuesen pobres. Así, los únicos cuerpos tolerables eran aquellos que pudieran esgrimir sin vergüenza la limpieza de sangre, como lo señalaba en su testamento un encomendero en la ciudad de Tunja hacia 1690: "He hallado (sic) será muy del agrado de Dios Nuestro Señor el fundar una escuela en que se enseñe a leer, escribir y contar a los pobres [...] por un religioso de la Compañía de Jesús de esta ciudad [...] en la cual se han de enseñar y recibir hasta un número de doscientos pobres, si los hubiere y con condición de que en la dicha escuela no se puede recibir indios, negros, mulatos, zambos, porque mi ánimo deliberado y voluntad expresa es excluirlos y que sólo se reciban los pobres españoles" (Martínez Boom y Silva, 1984: 53). De tal manera, en un medio de exclusión, las castas, de acuerdo a la "importancia" en la escalla social, no tenían otra oportunidad que la de pasar desapercibidas, mientras que los españoles pobres, aun con sus carencias, tenían toda la posibilidad de pavonearse mirando de soslayo a los excluidos por el color de la piel.

Así pues, durante la Colonia el cuerpo afrontó una especie de ocultamiento, en el que tanto las "vergüenzas" o el cuerpo propiamente dicho, tanto como el color de la piel, tendieron a mantenerse en la sombra, lejos de las miradas. Al mismo tiempo, la educación marchaba en esa dirección. El maestro para adquirir el empleo no sólo debía probar limpieza de sangre que era, a su vez, de alma, sino, lograr además "un espacio y un tiempo para su decir, pactando y sometiendo su cuerpo y su alma a la mirada pública y a los designios del poder estatal". De ahí que el maestro debiera realizar su función en una especie de doble juego: bajo la condición de formador de la juventud y de los vasallos, y aquella donde lo importante no fuese el ejercicio de su oficio, sino el ejemplo que pudiera despertar como centro de todas las miradas, motivo de rigurosa vigilancia, calificación y control; es decir, mediante el lucimiento de su presencia, su cuerpo en perfecta y diciente compostura (Martínez Boom, Castro Villarraga y Noguera, 1999).

Podría aducirse que con el paso del tiempo, algunos vicios se habían morigerado. Así, a principios del siglo XIX la asistencia de negros y mestizos a la escuela era ya permitida, aun con la resistencia que éstos oponían por la negación que durante tanto tiempo les habían impuesto (Álvarez Gallego, 1995). 
Sin embargo, los viejos prejuicios en torno al ocultamiento del cuerpo persistían y se hicieron evidentes con la reforma escolar de 1870, que, entre otras cosas, pretendía quitarle el monopolio de la educación al clero y delegarlo como instrucción pública al Estado. La reacción conservadora no se hizo esperar. En 1872 se propuso un nuevo proyecto que pretendía que todos los maestros de escuela fueran católicos para que no viciaran las costumbres de los niños y prohibía la enseñanza de cualquier precepto contrario al catolicismo; además, disponía el establecimiento de escuelas separadas para niños no católicos (Rausch, 1993). Este intento de reforma fue rápidamente aplacado con las guerras de las escuelas, así llamadas, que se desataron a raíz del intento de transformar la escuela por parte de los liberales, y el siglo XX sería recibido con un sistema educativo retrógrado y una sociedad mojigata dirigidos por el clero.

\section{Negación y posibilidad del cuerpo en el siglo XX}

A principios del siglo XX los viejos prejuicios coloniales de limpieza de sangre, expresados en la blancura del rostro (no del cuerpo, que continuaba oculto) todavía persistían. A ello vino a sumarse una preocupación más: la de que los mestizos (que eran en su mayoría la población colombiana) "racialmente" se estaban degenerando. El médico Miguel Jiménez López adujo que una degeneración colectiva afectaba a los colombianos tanto en el plano físico como el psíquico. La inferioridad biológica del pueblo se manifestaba en su pequeña estatura, además de diversos signos evidentes como el aumento de la locura, el alcoholismo y el rápido recurso al suicidio. Para regenerar la "raza", proponía la inmigración de nórdicos al país, quienes componían las fuerzas armadas de los Estados Unidos (Helg, 2001). Así pues, el concepto de cuerpo humano para las elites colombianas estaba ligado al prejuicio de blancura europea, aun sin advertir que para entonces la población colombiana era en su mayoría mestiza. Lo blanco era sinónimo no sólo de humano, sino de pureza, de castidad: "las personas buena y lindas eran las que se parecían a Jesús y a la Virgen" (Galeano, 1994: 32).

Muchos de los intelectuales de la época, como Luis López de Mesa, compartieron ese punto de vista. Sin embargo, aun cuando no fue llevado a efecto, la preocupación devino en la formulación de premisas que buscaban el cuidado del cuerpo mediante la higiene, resultado del aseo personal. Así, durante las primeras décadas del siglo XX "el cultivo del cuerpo adquirió un tinte particular", en razón de que las nuevas concepciones sobre el cuerpo dieron lugar a una subjetividad fundada en su cuidado activo y en su cultivo a través del movimiento y el uso racional de los sentidos, aspectos todos orientados al moldeamiento para el trabajo, manual, intelectual o espiritual.

De tal manera, tal preocupación recayó en la higiene moderna, que ya comenzaba a vincularse con las nociones de psicología experimental (Pedraza Gómez, 2001). Y es que, precisamente como señala Georges Vigarello (2005), el agua se consideraba un medio extraño y complejo, que podía ser susceptible de perjudicar al organismo porque lo perturbaba, impresionaba o debilitaba en función de la temperatura a la que se tomara. El baño se relacionaba con la medicina más que con la higiene corporal.

En este sentido, la preocupación del Estado por la higiene en las dos primeras décadas del siglo $\mathrm{XX}$, se hizo tan profunda que incluso se llegó a la expedición de un acuerdo en el que se formuló que "no se admitirá en las escuelas y colegios alumno alguno que estuviere atacado de enfermedad contagiosa", lo cual se puede interpretar como la necesidad del Estado por formar una figura "corporal distintiva", la del cuerpo sano. En otras palabras, el niño era susceptible de ser admitido en las escuelas siempre y cuando tuviese un cuerpo sano (Ospina López, 1990).

Al mismo tiempo, el cultivo del cuerpo estaba determinado tanto por la higiene como por la incipiente educación física. Así, la educación física, basada en el precepto de mente sana en cuerpo sano, se convirtió en una estrategia de salubridad a través de programas y campañas que tenían origen en la institución escolar, y ello precisamente a partir de la consideración de que las relaciones entre educación física y formación de la Nación en la primera mitad del siglo XX, se concretan en la articulación de la formulación del individuo con el orden social y el modelo económico, en el marco de las condiciones propias del proceso de modernización que producen una red de relaciones de prácticas y saberes sociales, derivadas del cuerpo, el juego, el deporte y el conjunto de producciones culturales de la actividad física, que expresan las características y responsabilidades de individuos y grupos sociales respecto a su pertenencia e identidad en una comunidad (Chinchilla, 2001: 160).

Al terminar la hegemonía conservadora (1886-1930), los liberales intentaron introducir severos cambios al decadente orden que había imperado durante casi cincuenta años. Eliminar los prejuicios medievales sobre el ocultamiento del cuerpo y la separación de sexos fue una de las medidas que se advirtieron en la reforma educativa introducida por los liberales. En el mismo sentido, 
los padres de familia fueron considerados instrumentos de la educación de sus hijos, y de ahí que, entre los Treinta mandamientos a los padres de familia de los escolares, entregados en septiembre de 1942, se les hicieran recomendaciones como éstas: "que los niños vayan siempre limpiamente vestidos al colegio, cuidadosamente lavados y con los dientes limpios"; "respeten la independencia de sus hijos y estimulen el uso creativo del tiempo libre"; "estimulen el deporte"; "estimulen la gimnasia"; "instruyan a tiempo a sus hijos sobre lo que concierne a la cuestión sexual para que la información que recojan sea la adecuada" (Muñoz y Pachón, 1996: 234).

Sin embargo, con la vuelta al poder de los conservadores a partir de 1946, los prejuicios y terrores sobre el cuerpo volvieron otra vez a escena, y la educación entonces no pretendió otro objetivo que el de formar buenos cristianos (Muñoz y Pachón, 1996: 255). La educación mixta fue prohibida a partir de 1949, y en este aspecto las escuelas fueron severamente vigiladas (Helg, 1998), pues la mezcla de sexos iba en contra de la naturaleza, según los preceptos del clero. En todo caso, con el paso del tiempo la realidad pudo más que las reformas y las imposiciones, pues la masificación, los medios de comunicación y la educación misma acarrearon desde los años sesenta una serie de transformaciones culturales que vendría a desvanecerse de manera rápida con el ingreso de esa ambigua postura ante la realidad conocida como condición posmoderna.

\section{El cuerpo posmoderno}

Desde finales del siglo XX, gracias a la difusión masiva de los mass media, la formación del cuerpo y su expresión es el resultado de la llamada realidad virtual. Un mundo en el que prima la imagen y cuyo origen y partida es exponer la inexistencia de un mundo asumido como realidad, como experiencia, como manifestación de un presente que, infortunadamente sólo existe en la pantalla. En este campo, como nos dice Peter McLaren (1997), el cuerpo es el punto central en la reiniciación dialéctica del significado y el deseo, y como sujetos/ cuerpo, no simplemente consumimos conocimiento cultural, sino que somos consumidos por él.

Infortunadamente, las transformaciones generadas por los mass media entre los jóvenes son inadvertidas por la misma escuela, aun cuando "el problema de las escuelas no radica en que ignoren los cuerpos, sus placeres, ni el sufrimiento de la carne (aunque se admite que ello es parte del problema), sino en que infravaloran el lenguaje y la representación, como factores constitu- tivos en la formación del cuerpo/sujeto como creador del significado, la historia, la raza y el género" (McLaren, 1997), y ello porque la identidad reside en la corporalidad; el cuerpo es el primer contacto con el mundo, la base de la experiencia, la expresión de significado.

El cuerpo en la era posmoderna, es un campo de significados, que intenta reproducir las imágenes que lo consumen y que consume. Así, el cuerpo ya no es una realidad cerrada, de límites definidos y ampliamente identificables, sino un molde reproducido una y otra vez, y que perfila no una identidad propia, sino un producto que ha originado la publicidad. El cuerpo se vislumbra como objeto de la cosmética, de la moda y se moldea desde la cirugía (en quienes desde lejos no advierten siquiera las desigualdades económicas), a partir de de los modelos que reproduce la llamada realidad virtual.

En una sociedad abiertamente capitalista, con severos abismos entre quienes han adquirido y quienes no tienen nada, el cuerpo se convierte en un recurso que se pone al servicio del comercio de infinidad de productos, y a su vez el cuerpo mismo es una mercancía. Consumimos imágenes, cuerpos en el cine, las revistas, las noticias (que son farándula, más que información objetiva) $\mathrm{y}$ transmisiones deportivas.

Al mismo tiempo, la noción que persiste en el imaginario colectivo es que el cuerpo es la expresión de todos los valores, tanto éticos como económicos; el cuerpo es la carta de presentación, lejos de cualquier otra competencia de carácter académico o intelectual. Es la sugerencia de la permanencia, el tiempo detenido en un instante, una imagen más de lo virtual.

En este mismo campo, el cuerpo en las actividades deportivas está lejos de encarnar una renovación más amplia de la cultura, una visión más tecnificada del espacio y más calculada del tiempo, una mirada, aunque progresiva y lenta, más democrática de los intercambios y de la sociabilidad (Vigarello, 2005). Por el contrario, el cuerpo es asumido como instrumento de competencia, de rendimiento en los deportes extremos; la finalidad del deporte está lejos de los argumentos que han nutrido a la educación física, es evidencia de que se perfila como producto y como límite.

El cuerpo humano no evolucionó para nadar, patear una pelota o para dar saltos mortales desde una plataforma. Sin embargo, desde que los seres humanos adquirimos el sentimiento del deporte y la competencia, se han inventado maneras de forzar nuestra anatomía hasta sus límites (Gore, 2000). La era posmoderna, sin embargo, extrema esas posibilidades, donde el triunfo 
como meta es igualmente efímero, como un relámpago más de la imagen.

Para terminar, frente a las nuevas concepciones culturales entorno al cuerpo que asumen los jóvenes en las escuelas y los estudiantes de educación física, es más que conveniente un replanteamiento del oficio en la enseñanza de ésta. Una mirada a la historia del cuerpo y sus implicaciones en la enseñanza de la educación físi$\mathrm{ca}$, tanto de los maestros en las instituciones educativas como de los formadores en las facultades, permitiría abordar la realidad actual de la sociedad, ya no formada por la escuela y la familia, como socializadores tradicionales, sino por los medios de información, la publicidad $\mathrm{y}$ todo cuanto se deriva de los mass media. (ID)

\section{Bibliografía}

Álvarez Gallego, A. (1995). Y la escuela se hizo necesaria. Bogotá: Cooperativa Editorial Magisterio-Sociedad Colombiana de Pedagogía.

Aquino, T. de. (2001). Summa Theologica. Madrid: Biblioteca de Autores Cristianos.

Chinchilla, V. J. (2001). Educación física y construcción de nación en la primera mitad del siglo XX. En Herrera, M. C. Educación y cultura política: una mirada multidisciplinar. Bogotá: Universidad Pedagógica Nacional-Plaza y Janés.

Colón, C. (1982). Textos y documentos completos. Madrid: Alianza Universidad.

Corbin, A., Courtine, J. J. y Vigarello, G. Historia del cuerpo II. De la Revolución Francesa a la Gran Guerra. Madrid: Taurus.

Corvalán, M. E. (1999). El pensamiento indígena en Europa. Bogotá: Planeta.

Fontana, J. (1994). Europa ante el espejo. Barcelona: Crítica

Galeano, G. (1994). Ser como ellos y otros artículos. México: Siglo XXI Editores.

García Sánchez, B. Y. (2007). De la educación doméstica a la educación pública en Colombia. Transiciones de la Colonia a la República. Bogotá: Universidad Distrital Francisco José de Caldas.

Gélis, J. (2005). El cuerpo, la Iglesia y lo sagrado. En Corbin A., Courtine, J. J. y Vigarello, G. Historia del cuerpo I. Del Renacimiento al Siglo de las Luces. Madrid: Taurus.

Gómez, S. P. (2001). Sentidos, movimiento y cultivo del cuerpo: política higiénica para la nación. En Herrera, M. C. Educación y cultura política: una mirada multidisciplinar. Bogotá: Universidad Pedagógica Nacional-Plaza y Janés

104 Gonzalbo Aizpuru, P. (1998). Familia y orden colonial. México: El Colegio de México

Gonzalbo Aizpuru, P. (2000). Historia de la educación en la época colonial. El mundo indígena. México: El Colegio de México.

González Boto, R. (2003). El Emilio y la educación física escolar. Buenos Aires. http://www.efdeportes.com/ Revista Digital, 65 (9).

Gore R. (2000). ¿Qué se necesita para forjar el cuerpo imbatible? En National Geographic. México: Editorial Televisa Internacional.

Helg, A. (1998). La educación en Colombia, 1946-1957. En Nueva Historia de Colombia-IV. Bogotá: Planeta.
Helg, A. (2001). La educación en Colombia: 1918-1957. Bogotá: Universidad Pedagógica Nacional-Plaza y Janés.

Kamen, H. (1999). La inquisición española. Barcelona: Crítica.

Las Casas, B. (1991). Brevísima relación de la destrucción de las Indias. Edición de André de Saint Lú. Madrid: Editorial Cátedra.

Locke, J. (1986). Algunos pensamientos concernientes a la educación. En Pensamientos sobre la educación. Madrid: Akal.

Martínez Boom, A. y Silva, R. (1984). Dos estudios sobre educación en la Colonia. Bogotá: Universidad Pedagógica Nacional-CISP.

Martínez Boom, A., Castro Villarraga, O. y Noguera, C. E. (1999). Maestro y vida cotidiana en Santafé colonial. Bogotá: Sociedad Colombiana de Pedagogía.

McLaren, P. (1997). Pedagogía crítica y cultura depredadora. Políticas de oposición en la era posmoderna. Barcelona: Paidós.

Muñoz C. y Pachón X. (1996). La aventura infantil a mediados de siglo. Bogotá: Planeta.

Ospina López, A. (1990). Escuela e higiene. Documentos Foro, 8. Bogotá: Fundación Foro Nacional por Colombia.

Platón. (1985). Diálogos. Estudio preliminar de Francisco Larroyo. México: Editorial Porrúa.

Rausch, J. M. (1993). La educación durante el federalismo. La reforma escolar de 1870. Bogotá: Instituto Caro y Cuervo-Universidad Pedagógica Nacional.

Romero, J. L. (2006). La Edad Media. México: Fondo de Cultura Económica.

Rösener, W. (1990). Los campesinos en la Edad Media. Barcelona: Crítica.

Roux, R. R. de. (1990). Dos mundos enfrentados. Bogotá: CapacitarCinep.

Sevilla I. de (1971). Los tres libros de las Sentencias, Santos Padres Españoles II. Introducción, versión y notas de Julio Campos Ruiz e Ismael Roca Meliá. Madrid: Biblioteca de Autores Cristianos.

Vigarello, G. (2005). Introducción. En Corbin A., Courtine, J. J. y Vigarello, G. Historia del cuerpo I. Del Renacimiento al Siglo de las Luces. Madrid: Taurus. 